\title{
Efektivitas Think Pair Share (TPS) dan Pembelajaran Langsung dengan Talking Stick (TS) ditinjau dari Prestasi dan Kemandirian Belajar
}

\author{
Doni Susanto*, Erny Untari, Indra Puji Astuti \\ Universitas PGRI Madiun, Madiun, Indonesia \\ *Coresponding Author: doni.susanto@unipma.ac.id
}

\begin{tabular}{l}
\hline \hline Article history \\
\hline Dikirim: \\
31-12-2021 \\
Direvisi: \\
02-01-2022 \\
Diterima: \\
03-01-2022 \\
Key words: \\
\hline
\end{tabular}

Penelitian ini merupakan penelitian eksperimental semu dengan desain faktorial 2 x 3 yang bertujuan untuk mengetahui manakah model pembelajaran yang memberikan prestasi belajar matematika yang paling baik antara siswa yang diajar dengan menggunakan TPS-TS atau DL-TS ditinjau dari kemandirian belajar siswa. Populasi penelitian ini adalah seluruh siswa MA Negeri kelas XI di Kabupaten Ngawi pada tahun pelajaran 2021/2022, sedangkan sampel penelitian ini adalah siswa kelas X MAN 2 Ngawi dan MAN 3 Ngawi. Teknik pengambilan sampel

Think Pair Share; Pembelajaran langsung; Talking Stick;

Kemandirian Belajar menggunakan stratified cluster random sampling. Pengumpulan data menggunakan metode dokumentasi, angket kemandirian belajar siswa dan tes prestasi belajar matematika. Teknik analisis data menggunakan anava dua jalan dengan sel tak sama.berdasarkan hasil penelitian, dapat disimpulkan bahwa (1) prestasi belajar matematika siswa yang diajar dengan TPS-TS lebih baik dari DL-TS (2) prestasi belajar matematika siswa dengan kemandirian belajar tinggi, sedang, dan rendah sama baik (3) pada setiap model pembelajaran, Prestasi belajar matematika siswa dengan kemandirian belajar tinggi, sedang, dan rendah sama baik (4) pada masing-masing kategori kemandirian belajar, prestasi belajar matematika siswa yang diajar dengan TPS-TS lebih baik dari DL-TS.

\section{PENDAHULUAN}

Agar memperoleh sumber daya manusia yang berkemampuan baik sehingga dapat berkompetensi di kancah luas salah satunya adalah dengan pendidikan. Pendidikan merupakan suatu proses untuk mewujudkan cita-cita dan menciptakan karakter bangsa. Tedapat berbagai macam ilmu pendidikan salah satunya adalah matematika. Matematika merupakan salah satu ilmu yang penting karena ilmunya banyak diterapkan dikehidupan sehari-hari. Akan tetapi hadirnya matematika di dalam dunia pendidikan menjadi momok yang menakutkan bagi para siswa (Kamarullah, 2017).

Matematika berhubungan dengan rumus dan angka sehingga menurut siswa matematika itu sulit, hal tersebut senada dengan apa yang diungkapkan Li \& Schoenfeld (2019) bahwa matematika umumnya dianggap sukar. Padahal Matematika ada bukan untuk menjadi sesuatu yang menakut-nakuti siswa. Matematika hadir untuk menata pemikiran siswa agar memiliki kemampuan untuk mengembangkan diri dalam matematika khususnya, maupun dalam berbagai disiplin ilmu lainnya. Langoban (2020) mengungkapkan ada 3 hal yang membuat matematika 
sulit bagi siswa yaitu guru, siswa itu sendiri dan lingkungan yang memiliki batas interaksi.

Didunia pendidikan terdapat berbagai macam karakter guru, ada yang galak, cepat emosi, suka menghukum dan lain sebagainya. Hal tersebut berdampak pada siswa, siswa kurang mengerti dengan materi yang diberikan sehingga prestasi siswapun kurang begitu baik. Ditambah lagi pembelajaran di kelas yang masih monoton ceramah sehingga terpusat pada guru akibatnya siswa menerima materi dengan pasif (Ahmed, 2013; Nurwadani dkk, 2021) ditekankan lagi oleh Abidin (2017) guru yang hanya menggunakan satu metode biasanya sukar menciptakan suasana kelas yang kondusif dalam waktu yang relatif lama. Salah satu faktor yang mempengaruhi aktivitas belajar siswa adalah adalah cara atau metode atau model pembelajaran yang dipakai oleh guru (Nurjanah, Putri, \& Handayani, 2018; Syarifuddin, 2018). Pasifnya pembelajaran juga dipengaruhi oleh model pembelajaran yang diterapkan.

Model pembelajaran yang dirasa tepat membuat siswa lebih aktif dalam proses pembelajaran yaitu model pembelajaran kooperatif. Model pembelajaran kooperatif merupakan model pembelajaran yang mengedepankan kerja antar anggota kelompok dan dapat menjadikan siswa mampu memecahkan berbagai masalah secara bersamasama sehingga tujuan pembelajaran dapat tercapai. Manfaat utama pembelajaran kooperatif yaitu meningkatkan rasa percaya diri siswa, yang pada akhirnya memotivasi siswa untuk berpartisipasi dalam proses pembelajaran, menghasilkan tingkat prestasi yang lebih tinggi oleh semua peserta, siswa saling membantu, membangun komunitas suportif yang meningkatkan kinerja setiap anggota, dan meningkatkan harga diri semua siswa. Lebih lanjut, Pembelajaran kooperatif adalah sebuah pendekatan dimana siswa terbagi dalam grup kecil yang bekerja bersama dalam tim untuk memecahkan permasalahan, menyelsaikan tugas untuk meraih tujuan bersama (Silalahi \& Hutauruk, 2020). Lebih lanjut, Ekeanyanwu, \& Anene (2020) mengungkapkan pada pembelajaran kooperatif siswa bekerja dengan kooperatif dalam kelompok kecil yang heterogen.

Salah satu model pembelajaran kooperatif yang dapat diterapkan untuk mengatasi permasalahan tersebut adalah model pembelajaran kooperatif Think Pair Share. Think Pair Share merupakan salah satu jenis pembelajaran kooperatif. Kegiatan pembelajaran ini lebih mengedepankan pada kegiatan yang mendorong siswa untuk aktif menemukan konsep keterampilan proses mereka sendiri. Think Pair Share memberi siswa waktu untuk berpikir dan saling menanggapi dan saling membantu. Misalnya, seorang guru baru saja menyelesaikan sebuah cerita pendek presentasi atau siswa telah selesai membaca tugas (Saragih, Yusnadi, dan Alesyanti, 2020). Kegiatan inti pembelajaran TPS memiliki tiga tahap, yaitu (1) tahap berpikir (think), (2) tahap berpasangan (pair) dan (3) tahap berbagi (share). TPS adalah jenis model pembelajaran yang mudah diterapkan agar siswa dapat bekerja sama, saling membantu, belajar memberi informasi atau keterampilan dan memiliki sistem penilaian untuk meningkatkan individu dan bekerja sama dalam kelompok (Tahir, Basri, \& Firdaus, 2019).

Pada model TPS, saat siswa membagikan hasil diskusi kelompok ada peluangsiswa yang pandai dalam kelompok ditunjuk untuk mempresentasikan hasil diskusinya sehingga anggota dalam kelompok hanya dapat mengandalkan siswa yang pandai tersebut. Begitu pula dengan pembelajaran langsung, hanya siswa pintar yang 
mampu mempresentasikan hasil karyanya. Untuk itu perlu dilakukan upaya agar hal tersebut tidak terjadi, salah satunya dengan menerapkan strategi pembelajaran. Salah satu strategi pembelajaran yang dapat digunakan guru dalam proses pembelajaran di kelas adalah Talking Stick. Strategi Talking Stick (TS) menggunakan tongkat sebagai alat penunjuk dengan memberikan kesempatan kepada siswa untuk bekerja sendiri dan bekerjasama dengan teman lainnya sehingga dapat mengoptimalkan partisipasi siswa, membuat siswa aktif, dan menciptakan suasana belajar yang menyenangkan. Talking stick merupakan model pembelajaran yang memungkinkan siswa aktif dan kreatif sehingga dapat dicapai hasil belajar kognitif siswa (Purba, 2021). Senada dengan hal tersebut, Meganingtyas, Winarni, \& Murwaningsih (2019) mengatakan Talking stick adalah strategi pembelajaran yang menunjukkan keberanian siswa dalam menjawab pertanyaan. Siswa yang menjawab pertanyaan akan dipilih dengan menggunakan tongkat. Pada penelitian ini model pembelajaran TPS dan pembelajaran langsung akan dipadukan dengan strategi Talking Stick.

Dari pemaparan tersebut, selain metode belajar mengajar yang kurang tepat sebagai faktor eksternal yang mempengaruhi keberhasilan pembelajaran juga terdapat faktor internal yang mempengaruhi keberhasilan pembelajaran. Faktor internal yang mungkin salah satunya adalah kemandirian belajar. Model pembelajaran mandiri merupakan upaya sistematis yang dilakukan oleh siswa dalam mangatur proses pembelajarannya dalam rangka mencapai penguasaan kompetensi secara utuh. Siswa dilatih secara mandiri untuk dapat meningkatkan kemampuan dan keterampilannya sendiri dalam proses belajar agar siswa tidak bergantung pada orang lain (Putri, Retno, \& Dj., 2018).

Berdasarkan uraian yang telah diuraikan sebelumnya, maka tujuan penelitian ini adalah untuk mengetahui: 1) model pembelajaran mana yang memiliki prestasi belajar matematika lebih baik antara model pembelajaran TPS dengan Talking Stick atau langsung dengan Talking Stick 2) kategori kemandirian belajar mana yang memiliki prestasi belajar matematika yang lebih baik pada siswa yang memiliki kemandirian belajar matematika tinggi, sedang atau rendah 3) mana yang memiliki prestasi belajar matematika yang lebih baik antara siswa yang memiliki kemandirian belajar tinggi, sedang atau rendah pada siswa yang diberi model pembelajaran TPS dengan Talking Stick atau langsung dengan Talking Stick 4) mana yang memiliki prestasi belajar yang lebih baik antara model pembelajaran TPS dengan Talking Stick atau langsung dengan Talking Stick pada siswa yang memiliki kemandirian belajar tinggi, sedang atau rendah.

\section{METODE PENELITIAN}

Penelitian ini adalah penelitian eksperimental semu. Variabel bebas pada penelitian ini adalah model pembelajaran dan kemandirian belajar matematika, sedangkan variabel terikatnya adalah prestasi belajar matematika. Model pembelajaran yang digunakan adalah model pembelajaran TPS dengan Talking Stick dan pembelajaran langsung dengan Talking Stick. Variabel bebas yang lainnya yang ikut mempengaruhi variabel terikat adalah kemandirian belajar dengan kategori tinggi, sedang, dan rendah. Rancangan penelitian yang digunakan pada penelitian ini adalah rancangan faktorial $2 \times 3$. Berikut rancangan penelitian. 
Tabel 1. Desain Faktorial Penelitian

\begin{tabular}{lllll}
\hline \multirow{2}{*}{ Model Pembelajaran $(\mathrm{m})$} & \multicolumn{3}{l}{ Kemandirian Belajar $(b)$} \\
\cline { 2 - 5 } & $\begin{array}{l}\text { Tinggi } \\
\left(n_{1}\right)\end{array}$ & $\begin{array}{l}\text { Sedang } \\
\left(n_{2}\right)\end{array}$ & $\begin{array}{l}\text { Rendah } \\
\left(\mathrm{n}_{3}\right)\end{array}$ \\
\hline $\begin{array}{l}\text { TPS dengan Talking Stick } \\
\left(\mathrm{m}_{1}\right)\end{array}$ & $(m n)_{11}$ & $(m n)_{12}$ & $(m n)_{13}$ \\
\hline $\begin{array}{l}\text { TPS dengan Talking Stick } \\
(\mathrm{m})\end{array}$ & $(m n)_{21}$ & $(m n)_{22}$ & $(m n)_{22}$ \\
\hline
\end{tabular}

Populasi pada penelitian ini adalah seluruh siswa kelas XI MA Negeri di Kabupaten Ngawi pada semester ganjil tahun ajaran 2021/2022 sedangkan sampel pada penelitian ini adalah siswa kelas X pada 2 MA Negeri di Kabupaten Ngawi, Jawa Timur yang diambil 3 kelas pada masing-masing sekolah. Pengambilan sampel menggunakan teknik stratified cluster random sampling. Adapun metode yang digunakan pada penelitian ini adalah metode dokumentasi, metode angket dan metode tes. Teknik analisis data yang digunakan untuk menguji hipotesis adalah analisis variansi dua jalan dengan sel tak sama uji komparasi ganda dengan uji Scheffe'. Sebelum dilakukan perhitungan dengan analisis variansi terlebih dahulu dilakukan uji prasyarat yaitu uji normalitas dengan metode Lilliefors, uji homogenitas dengan metode Bartllet serta uji keseimbangan dengan uji t.

\section{HASIL DAN PEMBAHASAN}

Berikut adalah rangkuman data prestasi belajar matematika pada kelompok eksperimen TPS-TS, kelompok eksperimen DL-TS yang tersaji pada Tabel 2.

Tabel 2. Rangkuman Deskripsi Data Prestasi Belajar Matematika

\begin{tabular}{llll}
\hline Kelompok & N & Rerata & Standar Deviasi \\
\hline TPS-TS & 85 & 79.312 & 10.625 \\
\hline DL-TS & 89 & 69.738 & 11.775 \\
\hline Kemandirian Belajar Tinggi & 63 & 73.221 & 11.779 \\
\hline Kemandirian Belajar Sedang & 64 & 72.875 & 11.553 \\
\hline Kemandirian Belajar Rendah & 58 & 72.336 & 11.375 \\
\hline
\end{tabular}

\section{A. Uji Prasyarat}

\section{Uji Normalitas}

Uji normalitas digunakan untuk mengetahui apakah data dari sampel penelitian berasal dari populasi yang berdistribusi normal. Pada penelitian ini, uji normalitas menggunakan metode Lilliefors. Berikut adalah hasil uji normalitas dengan taraf signifikansi $5 \%$.

Tabel 3. Hasil Uji Normalitas Data Kemampuan Awal

\begin{tabular}{clll}
\hline Kelompok & Lobs & Ltabel $_{\text {Kesimpulan }}$ & Normal \\
\hline TPS-TS & 0,0870 & 0,0950 & Normal \\
\hline DL-TS & 0.0784 & 0,0934 & .
\end{tabular}

Berdasarkan Tabel 3 dapat diketahui pada masing-masing kelompok eksperimen, $\mathrm{L}_{\mathrm{obs}}<\mathrm{L}_{\text {tabel }}$ sehingga dapat disimpulkan masing-masing sampel berasal dari populasi yang berdistribusi normal. 
Tabel 4. Hasil Uji Normalitas Data Prestasi Belajar

\begin{tabular}{clll}
\hline Kelompok & Lobs & Ltabel & Kesimpulan \\
\hline $\boldsymbol{m}_{\mathbf{1}}$ & 0,0777 & 0,0950 & Normal \\
\hline $\boldsymbol{m}_{\mathbf{2}}$ & 0,0883 & 0,0934 & Normal \\
\hline $\boldsymbol{n}_{\mathbf{1}}$ & 0,0755 & 0,0919 & Normal \\
\hline $\boldsymbol{n}_{2}$ & 0,0833 & 0,0895 & Normal \\
\hline$n_{3}$ & 0,0885 & 0,1030 & Normal \\
\hline
\end{tabular}

Berdasarkan Tabel 4 dapat dilihat bahwa semua nilai $L_{\text {obs }}<L_{\text {tabel }}$ sehingga dapat disimpulkan pada masing-masing kelompok berasal dari populasi yang berdistribusi normal.

\section{Uji Homogenitas}

Uji homogenitas digunakan untuk mengetahui apakah populasi penelitian mempunyai variansi yang sama atau tidak. Untuk menguji homogenitas ini digunakan metode Bartllet dengan statistik uji Chi kuadrat.

Berikut dalah hasil uji homogenitas dengan taraf signifikansi $5 \%$.

Tabel 5. Hasil Uji Homogenitas Data Kemampuan Awal

\begin{tabular}{ccc}
\hline Kelompok & $X_{\text {obs }}^{2}$ & $X_{\text {tabsi }}^{2}$ \\
\hline$m_{1}, m_{2}$ & 2,335 & 3,841 \\
\hline
\end{tabular}

Berdasarkan Tabel 5 dapat dilihat $X_{o b s}^{2}<X_{\text {tabel }}^{2}$ maka dapat disimpulkan bahwa pada nilai kemampuan awal kedua kelompok eksperimen mempunyai variansi yang sama atau homogen.

Tabel 6. Hasil Uji Homogenitas Data Prestasi Belajar

\begin{tabular}{lcc}
\hline Kelompok & $X_{\text {obs }}^{2}$ & $X_{\text {tabel }}^{2}$ \\
\hline$m_{1}, m_{2}$ & 2,557 & 3,841 \\
\hline$n_{1}, n_{2}, n_{3}$ & 2,773 & 5,991
\end{tabular}

Berdasarkan Tabel 6 dapat dilihat semua $X_{o b s}^{2}<X_{t a b e l}^{2}$ maka dapat disimpulkan bahwa pada semua kelompok mempunyai variansi yang sama atau homogen.

\section{Uji Keseimbangan}

Uji keseimbangan dilakukan pada tiga kelompok pada saat sebelum dikenai perlakuan dengan tujuan untuk mengetahui apakah ketiga kelompok tersebut memiliki kemampuan awal yang seimbang atau tidak. Statistik uji yang digunakan dalam uji keseimbangan rata-rata adalah uji t.

Berikut adalah hasil uji keseimbangan dengan taraf signifikansi 5\%. 
Tabel 7. Hasil Uji Keseimbangan Data Kemampuan Awal

\begin{tabular}{lll}
\hline $\mathrm{t}_{\mathrm{obs}}$ & $\mathrm{t}_{\text {tabel }}$ & Kesimpulan \\
\hline 0,393 & 2,261 & Seimbang
\end{tabular}

Pada Tabel 7 dapat dilihat bahwa $t_{o b s}<t_{\text {tabel }}$ sehingga dapat disimpulkan bahwa ketiga kelompok eksperimen mempunyai kemampuan awal yang seimbang atau sama.

\section{Uji Hipotesis}

Hasil perhitungan uji hipotesis dengan analisis variansi dua jalan $2 \times 3$ dengan sel tak sama dan taraf signifikansi 5\% disajikan pada Tabel 8 berikut.

Tabel 8. Rangkuman Analisis Variansi Dua Jalan dengan Sel Tak Sama

\begin{tabular}{ccccccc}
\hline Sumber & $\mathrm{JK}$ & $\mathrm{dK}$ & $\mathrm{RK}$ & $\mathrm{F}_{\text {obs }}$ & $\mathrm{F}_{\text {tabel }}$ & Keputusan \\
\hline MODEL(M) & 2655,721 & 1 & 2643,531 & 5,731 & 3,897 & H0 ditolak \\
\hline KEMANDIRIAN(N) & 727,658 & 2 & 371,850 & 1,708 & 3,049 & H0 diterima \\
\hline INTERAKSI(MN) & 313,571 & 2 & 165,220 & 0,772 & 3,049 & H0 diterima \\
\hline Galat & 72321,523 & 175 & 435,665 & & & \\
\hline Total & 73876,853 & 176 & & & & \\
\hline
\end{tabular}

Berdasarkan rangkuman hasil analisis variansi dua jalan dengan sel tak sama dengan taraf signifikansi 5\% pada Tabel 8 dapat disimpulkan bahwa.

a. Pada efek utama A (model pembelajaran), yaitu 5,371> 3,897 sehingga ditolak. Hal ini berarti terdapat perbedaan prestasi belajar matematika antara siswa yang diajar dengan model pembelajaran TPS dengan Talking Stick dan DL dengan Talking Stick sehingga prestasi belajar matematika antara siswa yang diajar dengan model pembelajaran TPS dengan Talking Stick lebih baik dari siswa yang yang diajar dengan DL dengan Talking Stick.

b. Pada efek utama B (tingkat kemandirian belajar, yaitu 1,708 $<3,049$ sehingga diterima. Hal ini berarti tidak terdapat perbedaan prestasi belajar matematika siswa antara siswa yang mempunyai tingkat kemandirian belajar tinggi, sedang, dan rendah sehingga prestasi belajar matematika antara siswa dengan tingkat kemandirian belajar tinggi, sedang, dan rendah adalah sama. Hal tersebut senanda dengan Tampubolon (2020) prestasi belajar matematika antara siswa dengan tipe kemandirian belajar tinggi, sedang, dan rendah adalah sama baik.

c. Pada efek interaksi AB (model pemebelajaran dan tingkat kemandirian belajar), yaitu $0,772<3,049$ sehingga diterima. Hal ini berarti tidak terdapat interaksi antara model pembelajaran dan kemandirian belajar siswa terhadap prestasi belajar Matematika siswa. Sutrisno, Konaah, dan Indiati, (2019) juga menegaskan bahwa tidak adanya interaksi antara model pembelajaran dengan kemandirian belajar siswa.

Berdasarkan hasil uji anava dua jalan, hipotesis pertama hipotesis nol ditolak, maka perlu dilakukan uji komparasi ganda pada hipotesis tersebut. 
Tabel 9. Rerata Sel dan Rerata Marginal

\begin{tabular}{cllll}
\hline \multirow{2}{*}{ Model } & \multicolumn{2}{l}{ Kemandirian Belajar } & \multirow{2}{*}{ Marginal } \\
\cline { 2 - 4 } & $\mathrm{T}$ & $\mathrm{S}$ & $\mathrm{R}$ & 78,554 \\
\hline TPS-TS & 81,667 & 76,771 & 75,338 & 65,579 \\
\hline DL-TS & 70,327 & 68,997 & 68,875 & \\
\hline Marginal & 75,995 & 72,884 & 72,106 & \\
\hline
\end{tabular}

Adapun uji komparasi ganda dengan menggunakan metode Scheffe' sebagai berikut.

\section{Uji Komparasi Ganda Antar Baris}

Tabel 10. Rangkuman Komparasi Ganda Antar Baris

\begin{tabular}{cccc}
\hline Baris & Fobs $_{\text {or. }}$ & F $_{\text {tabel }}$ & Keputusan \\
\hline F $_{1 .-2}$ & 17,567 & 6,099 & H0 ditolak \\
\hline
\end{tabular}

Berdasarkan Tabel 10 maka dapat disimpulkan bahwa Pada $H_{0}: \mu_{.1}=\mu_{.2}$ keputusan ujinya $\mathrm{H}_{0}$ ditolak karena $F_{o b s}>2 F_{0,05,2,169}$ yaitu $17,567>6,099$. Hal ini berarti siswa yang diajar dengan TPS-TS menghasilkan prestasi belajar yang lebih baik daripada siswa yang diajar menggunakan model DL-TS. Hal itu dapat dilihat dari rataan marginal $\overline{X_{1}}=78,554>65,579=\overline{X_{2}}$.

\section{KESIMPULAN}

Berdasarkan hasil penelitian dan pembahasan sebelumnya maka dapat disimpulkan sebagai berikut.

1. Model pembelajaran TPS dengan Talking Stick menghasilkan prestasi belajar Matematika yang lebih baik dari model pembelajaran DL dengan Talking Stick.

2. Prestasi belajar Matematika siswa yang mempunyai kemandirian belajar tinggi, sedang dan rendah yang sama baik.

3. Pada setiap model pembelajaran, siswa yang mempunyai kemandirian belajar tinggi, sedang, dan rendah menghasilkan prestasi belajar yang sama baik.

4. Pada setiap kategori kemandirian belajar, model TPS dengan Talking Stick menghasilkan prestasi belajar yang lebih baik daripada DL dengan Talking Stick.

\section{DAFTAR PUSTAKA}

Abidin, A. M., (2017). Kreativitas Guru Menggunakan Model Pembelajaran Dalam Meningkatkan Hasil Belajar. Didaktika: Jurnal Kependidikan, 11 (02), 225-238

Ahmed, A. K., (2013). Teacher-Centered Versus Learner-Centered Teaching Style. The Journal of Global Business Management. 09 (01), 22-34

Ekeanyanwu, S. N. \& Anene, J. N. (2020). A Comparative Study of Cooperative And Conventional Learning Strategies On Academic Achievement Of Students In Biology. International Journal of Education and Research. 08 (10), 173 - 186

Kamarullah. (2017). Pendidikan Matematika di Sekolah Kita. AlKhawarizmi: Jurnal Pendidikan dan Pembelajaran Matematika, 01 (01), 21-32 
Langoban, M. A. (2020). What Makes Mathematics Difficult as a Subject for most Students in Higher Education?. International Journal of English and Education. 09 (03), 214-220

Li, Y.,\& Schoenfeld, H. (2019). Problematizing Teaching and Learning Mathematics as Given in STEM Education. International Journal of STEM Education, 06 (44), 1-13

Meganingtyas, B. R., Winarni, R.,\& Murwaningsih, T. (2019). The effect of using course review horay and talking stick learning methods towards social science learning result reviewed from learning interest. International Journal of Educational Research Review, 04 (02), 190-197.

Nurjanah. A., Putri, A. D.,\& Handayani, T. (2018). Penerapan Model Pembelajaran Aktif Tipe Student Facilitator and Explaining (SFE) Terhadapa Aktivitas Belajar Siswa. Jurnal Penelitian Pendidikan Matematika, 02 (02), 123-133

Nurwadani, P. A., Syarifuddin, S., Gunawan, G., \& Dusalan, D. (2021). Hubungan Model Pembelajaran Kooperatif Tipe Numbered Head Together (NHT) terhadap Minat dan Hasil Belajar Siswa di Kelas VII SMP Negeri 4 Kota Bima Tahun Pelajaran 2021/2022. DIKSI: Jurnal Kajian Pendidikan dan Sosial, 2(1), 25-38.

Purba, I. R., (2021). Talking Stick Learning Model Test on Biology Students Cognitive Learning Outcomes. International Journal of Educational Research \& Social Sciences. 02 (01), 86-91

Putri, W. T. A., Retno, Y.,\& Dj. R. (2018). Perbandingan Hasil Belajar Siswa Dengan Model Pembelajaran Mandiri Dan Kooperatif Tipe Investigasi Kelompok Pada Sistem Reproduksi. Edusains: Jurnal Pendidikan Sains \& Matematika, 06 (02), 54-60

Saragih, M., Yusnadi,\& Alesyanti. (2020). The Influence of Cooperative Learning Models of Think Pair Share Types and Social Attitudes towards Learning Outcomes Theme of Deliberation in the Contents of Learning of Student Citizenship Education in Class V of Medan Experimental SDN. Budapest International Research and Critics Institute- Journal. 03 (01), 511-521

Silalahi, T. F.,\& Hutauruk, A. F. (2020). The Application of Cooperative Learning Model during Online Learning in the Pandemic Period. Budapest International Research and Critics Institute- Journal. 03 (03), 1683-1691

Sutrisno, Konaah, S.,\& Indiati, I. (2019). Efektifitas Model Pembelajaran Kooperatif Tipe Jigsaw terhadap Kemampuan Berpikir Kritis Matematis dan Kemandirian Belajar Siswa. Media Penelitian Pendidikan: Jurnal Penelitian dalam Bidang Pendidikan dan Pengajaran, 13 (02), 163 - 172

Syarifuddin, S. (2018). Pengaruh Pembelajaran Kooperatif Tipe Jigsaw Dan Tipe Group Investigation (GI) Terhadap Ketercapaian Kompetensi Dan Kemampuan Komunikasi Matematika Siswa Di SMA. Jurnal Ilmiah Mandala Education, 4(1), 163-172.

Tahir, S. R., Basri, M. I., \& Firdaus, A. M. (2019). Improving Students' Mathematics Outcame Through The Implementation of Think Pair Share Model. International Journal on Teaching and Learning Mathematics. 02 (02), 67 - 77 
Tampubolon, B. (2020). Motivasi Belajar dan Tingkat Belajar Mandiri Dalam Kaitannya Dengan Prestasi Belajar Mahasiswa. Jurnal Pendidikan Ilmu Pengetahuan Sosial Indonesia. 05 (02), 34 - 41 